\title{
A Basic Study on Synthetic Judgement of Shipping Safety
}

\author{
Zhao Jing-song, Wu Zhao-lin and Wang Feng-chen
}

(Dalian Maritime University)

Some statistics of marine accidents and the corresponding methods of safety assessment are analysed briefly in this paper. A synthetic judgement model of shipping safety is established by the use of fuzzy mathematics. On the basis of inquiries to more than 50 experts and scholars, the weight vector has been obtained. Finally, the level of shipping safety has been assessed synthetically by use of the data on major marine accidents which occurred during the period from January 1982 to June 1984 .

I. INTRODUCTION. The problem of ensuring shipping safety has been given close attention for more than a hundred years, especially in recent times. Many measures have been taken to address this problem. However, before a measure is introduced, it is important to be clear on the existing level of safety. Only by discovering the significant problems can appropriate measures be taken. Many experts and scholars at home and abroad have done a great deal of work in this area over many years. For example, Captain A. N. Cockcroft has made a statistical study of collisions at sea all over the world since World War II, the US National Transport Committee made a survey of all collision accidents occurring in the ten-year period from 1970 to 1979 , a Norwegian team investigated the collisions and strandings of Norwegian vessels in the nine-year period from 1970 to 1978 , the Japanese have recorded major accidents occurring from 1975 to 1980, IMO has recorded the serious oil tanker accidents occurring from 1968 to 1980, and so on. All these studies have given valuable results.

Although the level of safety could be evaluated from several aspects, it is necessary to take a wide view to achieve a general measure of shipping safety. Past studies on this subject have usually been single index judgements only, and cannot meet the above requirement. For instance, we could take the number of accidents $\left(N_{\mathrm{A}}\right)$, the number of lives lost $\left(N_{\mathrm{LL}}\right)$, and the number of ships totally lost $\left(N_{\mathrm{LS}}\right)$ as the indices to assess shipping safety separately, and the values of the above three indices might be 112,82 and 47 respectively in a certain waterway before a traffic separation scheme (Tss) is established, and 86,125 and 60 respectively after the rss is established in this waterway. If we use the single index method to evaluate the level of shipping safety of this waterway, we could not conclude whether the rss is effective or not, because while the $N_{\mathrm{A}}$ decreases, both $N_{\mathrm{LL}}$ and $N_{\mathrm{LS}}$ increase. So, we must synthesize or combine every relevant factor into one composite index to evaluate the level of shipping safety, and it is then possible to compare the level of shipping safety for a certain waterway in different periods, or the level of shipping safety for a certain period in different waterways.

2. A SYNTHETIC JUdGement MODEl OF Shipping Safetr. Synthetic judgement is a widely-used method in fuzzy mathematical theory. The central concept is to select some indices which are thought to be worth considering from the quantity to be judged, such as the three indices described above, and to give different weights to each index according to their relative importance; then to combine every index with its weight so that a general evaluation can be obtained. This method can be outlined as follows.

Let index set $U=\left\{U_{1}, U_{2}, \ldots, U_{m}\right\}$, the number of indices is $m$ (the index set 
$U=\left\{N_{\mathrm{A}}, N_{\mathrm{LL}}, N_{\mathrm{LS}}\right\}$ in the above example), and let unit set $V=\left\{V_{1}, V_{2}, \ldots, V_{n}\right\}$, the number of units is $n$. Here, the units can represent a group of shipping companies, or countries, or waterways, or accidents of different kinds, or ships of different type, or different periods of time, etc. For example, we can let the unit set $V=$ \{from January to December in 1982, from January to December in 1983 , from January to June in $1984\}$.

TABLE I. THE MAJOR ACCIDENTS OF SHIPS ABOVE 5000 G.R.T.

\begin{tabular}{|c|c|c|c|c|c|c|c|c|c|c|c|c|c|c|c|}
\hline \multirow[b]{2}{*}{ Month ... } & \multicolumn{11}{|c|}{1982} & \multicolumn{4}{|c|}{1983} \\
\hline & I & 2 & 3 & 4 & 5 & 6 & 8 & 9 & ro & II & 2 & I & 2 & 3 & 4 \\
\hline$N_{\mathrm{A}}$ & 9 & 13 & $\mathrm{t} t$ & 4 & 24 & II & 10 & 8 & $I_{3}$ & 13 & 3 & II & 16 & I I & 8 \\
\hline$N_{\mathrm{LL}}$ & 3 & 47 & 6 & - & 12 & 31 & 9 & 16 & I & - & 3 & - & - & $I_{3}$ & I \\
\hline \multirow[t]{2}{*}{$N_{\mathrm{LS}}$} & 2 & 1 & 3 & - & 9 & 4 & 5 & 4 & 3 & 2 & 6 & 3 & 7 & 3 & 3 \\
\hline & \multicolumn{7}{|c|}{1983} & \multicolumn{6}{|c|}{1984} & \multirow{2}{*}{\multicolumn{2}{|c|}{ Total }} \\
\hline Month ... & 5 & 6 & 8 & 9 & 10 & 11 & 12 & I & 2 & 3 & 4 & 5 & 6 & & \\
\hline$N_{\mathrm{A}}$ & 6 & 10 & 8 & II & 13 & 15 & 10 & 11 & 10 & 15 & 8 & 8 & 9 & 309 & \\
\hline$N_{\mathrm{LL}}$ & - & - & - & - & 24 & $8 I$ & - & 16 & - & -- & 3 & 3 & 7 & 276 & \\
\hline$N_{\mathrm{LS}}$ & - & 3 & 2 & 2 & 6 & 8 & 3 & 7 & 6 & 3 & 4 & 3 & 6 & 108 & \\
\hline
\end{tabular}

The single index judgement matrix $R$ is as follows :

$$
\begin{gathered}
R=\left[\begin{array}{cccc}
r_{11} & r_{12} & \ldots & r_{1 n} \\
r_{21} & r_{22} & \ldots & r_{2 n} \\
\ldots & \ldots & \ldots \\
r_{m 1} & r_{m 2} & r_{m n}
\end{array}\right] \\
r_{i j}=U_{R}\left(U_{i}, V_{j}\right) \quad\left(\circ \leqslant r_{i j} \leqslant \mathrm{I}\right)
\end{gathered}
$$

where $r_{i j}$ is the value of unit $j$ weighted with index $i(i=1,2, \ldots, m ; j=1,2 \ldots, n)$ and:

$$
\sum_{j=1}^{n} r_{i j}=1
$$

From the method of combining matrices when $R$, which determines a transformation, and $A$, a fuzzy sub-set of $U$, are given, then $B$, a fuzzy sub-set of $V$, can be determined as follows :

$$
\begin{gathered}
B=A \circ R \\
\left.A=a_{1}, a_{2}, \ldots, a_{m}\right)
\end{gathered}
$$

where $A$ is a weighting factor which is established according to the different value of every index affecting shipping safety, and $a_{i}$ represents the value of index $i$ affecting safety. On the basis of inquiries to more than 50 experts and scholars, the weighting vector in respect of $N_{\mathrm{A}}, N_{\mathrm{LL}}$ and $N_{\mathrm{LS}}$ was obtained as follows :

$$
A=\left(0.1934,0.3416,0.465^{\circ}\right)
$$

3. ThE LeVEl OF SHIPPING SAFETy. According to Lloyd's Ship Manager, major 
accidents to ships above 5000 g.r.t. occurring in the period from January 1982 to June 1984 , except for July in 1982 and July in 1983 , were as recorded in Table 1 . The varying trends of $N_{\mathrm{A}}, N_{\mathrm{LL}}$ and $N_{\mathrm{LS}}$ are presented in Fig. I using the single index method.

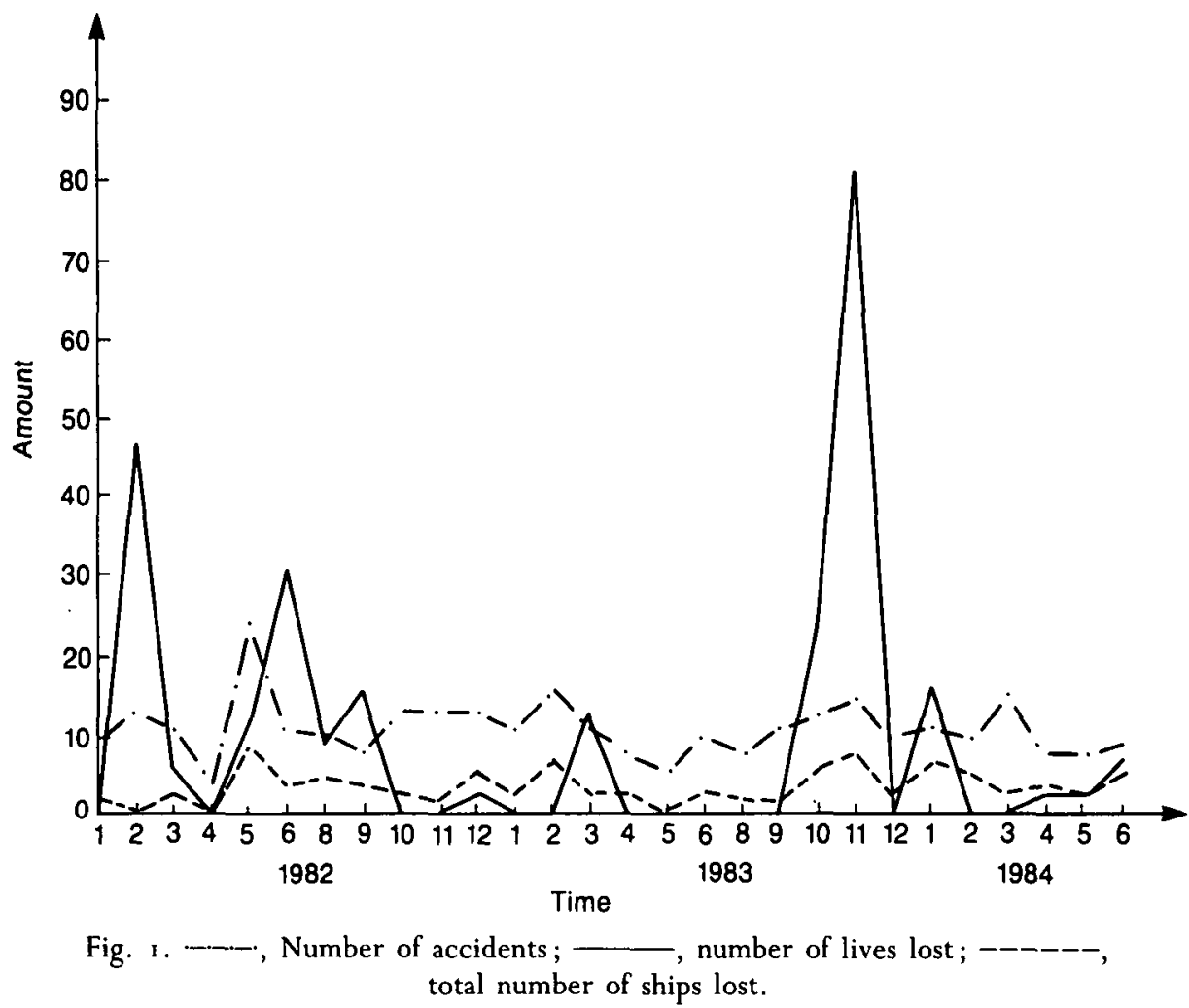

Comparing the data for February and May in 1982, although the $N_{\mathrm{A}}$ was 11 less and $N_{\mathrm{LS}}$ was 8 less in February than in May, $N_{\mathrm{LL}}$ was 35 more in February than in May. So it is not possible to say which one is safer. Now we assess the data of these two months, using the synthetic judgement model as follows.

From the data listed in Table 1 , the matrix $R$ is established as formula (7).

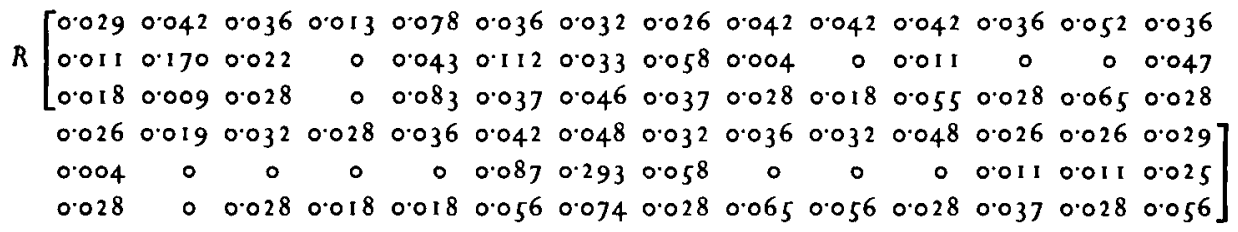

By putting formulae (6) and (7) into formula (4), the results of synthetic judgement $B$ can be obtained as in Fig. 2, from which the varying trend in the level of shipping safety can be seen clearly.

4. CONCLUSION. A synthetic judgement model of shipping safety has been outlined. This safety assessment method is very suitable for maritime safety administrations and shipping companies to assess the risk of different kinds of accidents 


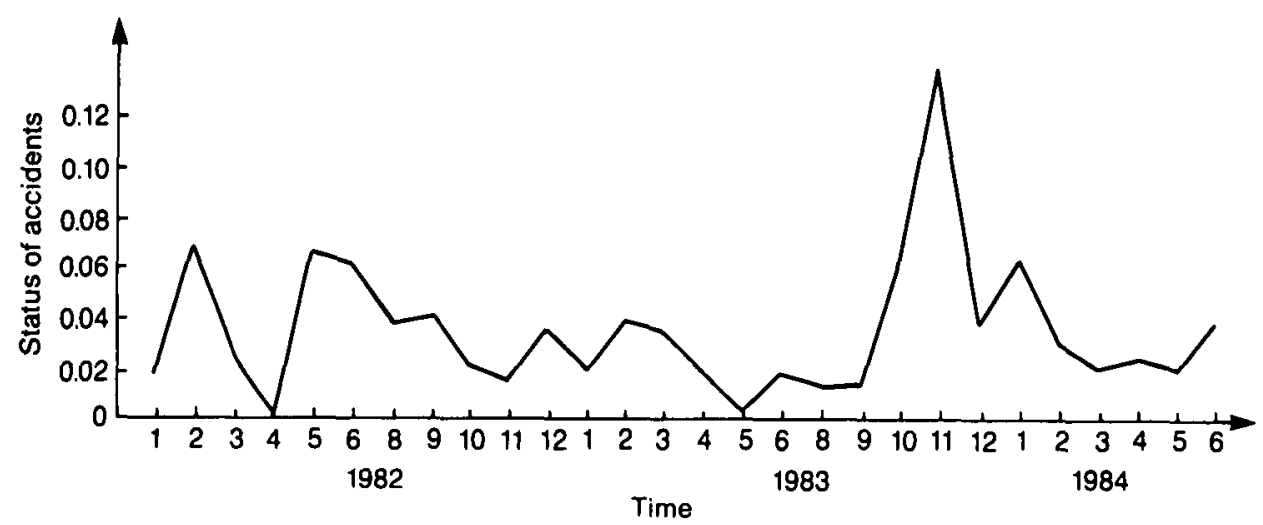

Fig. 2

and the effectiveness of newly-introduced safety measures. Its use could lead to more effective safety management.

KEY WORDS

1. Risk analysis. 2. Safety.

\title{
'Fuel Planning in Small Power Craft'
}

\author{
from George Huxtable
}

Tim Bartlett's thought-provoking article on fuel planning in small power craft $^{1}$ in the September 1991 issue of the Journal shows some shortcomings which hamper understanding of this topic.

(1) In his Figure 3, 'engine performance data', there are large discrepancies between the two scales of torque, in lbf and in Newton-metres, which are not even proportional to each other. Assuming the $\mathrm{Nm}$ scale to be correct, the power output calculated from torque times speed diverges significantly from the 'power curve to $\mathrm{BS} \mathrm{AU}_{4} \mathrm{I}$ ' shown in the same diagram (an amended Fig. 3 is shown here). These errors do not affect the author's arguments, but are likely to puzzle anyone who tries to use these data to evaluate them, as I did.

(2) The calculation of power-required makes the big assumption that at maximum output the engine is running at its rated speed and supplying maximum torque at that speed, and then scales down this maximum power according to some law at lower speeds. This assumes that the propeller has been correctly chosen to match exactly the engine characteristics at maximum output. Propeller-matching is, however, an inexact science, so how is the owner or the charterer to know that it has been done correctly?

(3) The author accepts that his momentum theory argument used to derive his 'propeller law' has several fundamental fallacies, but he has compounded the problems by using the same letter, $V$, to express two fundamentally different quantities. When he assesses the momentum transfer, $V$ represents the change in velocity of the water 